Check for updates

Cite this: RSC Adv., 2017, 7, 22008

Received 11th February 2017

Accepted 29th March 2017

DOI: 10.1039/c7ra01732d

rsc.li/rsc-advances

\section{Acidic hierarchical zeolite ZSM-5 supported Ru catalyst with high activity and selectivity in the seleno-functionalization of alkenes $\uparrow$}

\author{
Hai Dong, Lei Zhang, Zhongxue Fang, Wenqian Fu, ${ }^{*}$ Ting Tang, Yu Feng \\ and Tiandi Tang $\mathbb{D}$ *
}

\begin{abstract}
The acidic hierarchical zeolite ZSM-5 $(\mathrm{HZSM}-5-\mathrm{H})$ was synthesized for the preparation of a supported Ru catalyst (Ru/HZSM-5-H). The obtained Ru/HZSM-5-H catalyst shows high activity and product selectivity in the seleno-functionalization of alkenes compared to $\gamma-\mathrm{Al}_{2} \mathrm{O}_{3}$, basic ETS-10 and acidic microporous zeolite ZSM-5 supported Ru catalysts $\left(\mathrm{Ru} / \gamma-\mathrm{Al}_{2} \mathrm{O}_{3}, \mathrm{Ru} / \mathrm{ETS}-10\right.$ and $\mathrm{Ru} / \mathrm{HZSM}-5$, respectively), as well as a homogeneous $\mathrm{RuCl}_{3}$ catalyst. The relatively strong acidic sites in $\mathrm{Ru} / \mathrm{HZSM}-5-\mathrm{H}$ could benefit the adsorption of styrenes and the activation of the $\mathrm{C}=\mathrm{C}$ bond. Meanwhile, $\mathrm{Ru}^{4+}$ in $\mathrm{Ru} / \mathrm{HZSM}-5-\mathrm{H}$ could facilitate the formation of electrophilic selenium species as compared to $\mathrm{Ru}^{0}$ species. In addition, the Ru/ HZSM-5-M catalyst exhibits broad substrate compatibility in the difunctionalization of alkenes.
\end{abstract}

\section{Introduction}

The difunctionalization of alkenes is a flexible approach for constructing various functional compounds in modern organic synthesis..$^{1-3}$ For example, seleno-functionalized compounds are valuable intermediates as they can be used as building blocks in the preparation of various valuable, biologically active and natural products. ${ }^{4-6}$ The difunctionalization of alkenes can be realized through attacking the $\mathrm{C}=\mathrm{C}$ bond of alkenes with electrophilic selenium species followed by reacting with other nucleophilic reagents. ${ }^{1,7,8}$ Until now, this type of reaction was almost achieved in homogeneous catalytic systems. Also, to improve the reaction activity, various additives such as expensive metal organic salts, ${ }^{1,9,10}$ trimethylsilyl trifluoromethanesulfonate ${ }^{11}$ and toxic halogens ${ }^{12}$ were required to generate the electrophilic selenium species from diaryl diselenides. In these cases, the reaction systems were not only limited by the range of substrates, but they also had disadvantages, such as the tedious work-up separation and purification of the products and difficulty in reusing the catalysts, ${ }^{13,14}$ which severely limits their potential application. From a practical point of view, to realize a simple and clean process for the seleno-functionalization of a broad range of alkenes, developing functional heterogeneous catalysts with high efficiencies is of great significance. To achieve this aim, the following basic but critical aspects should be taken into account.

Advanced Catalysis and Green Manufacturing Collaborative Innovation Center, School of Petrochemical Engineering, Changzhou University, Changzhou, Jiangsu 213164, P. R.China.E-mail: fuwenqian@cczu.edu.com; tangtiandi@cczu.edu.cn; tangtiandi@ wzu.edu.cn; Tel: +86-519-86330253

$\dagger$ Electronic supplementary information (ESI) available. See DOI: $10.1039 / \mathrm{c} 7 \mathrm{ra} 01732 \mathrm{~d}$
(1) The catalyst should contain two active sites, where one can benefit the activation of the $\mathrm{C}=\mathrm{C}$ bond in alkenes and the other can facilitate the formation of the electrophilic selenium species using eco-friendly oxidizing agents $\left(\mathrm{H}_{2} \mathrm{O}_{2}\right.$ or $\left.\mathrm{O}_{2}\right)$. This would lead to the easier occurrence of the electrophilic selenium species attacking the activated $\mathrm{C}=\mathrm{C}$ bond in alkenes on the catalyst. (2) The catalyst should contain a porous structure that benefits the fast diffusion of the bulk reactants, and presents good chemical and mechanical stability under reaction conditions.

It is well known that crystalline porous aluminosilicate zeolites have good chemical and mechanical stability, modifiable surface properties (acid-basicity) and unique framework structures, and are widely used as supports for metal catalysts in the petrochemical and fine chemical industries. ${ }^{15-17}$ Recent studies have shown that organic substrates can interact with the surface acidic or basic sites of zeolites, ${ }^{18,19}$ and the electronic properties of the metal species could be modified by the zeolite's framework ${ }^{20-22}$ leading to the catalysts showing high activity and selectivity. Furthermore, the hierarchically porous structure of the zeolite crystals could benefit the mass transfer of the reactive substrates and products, ${ }^{23-25}$ improving the reaction activity and selectivity. Therefore, zeolites with hierarchically porous structures should be good candidates for the preparation of functional metal catalysts with high activity and good selectivity.

In this work, we prepared an acidic hierarchically porous zeolite ZSM-5 (HZSM-5-H) for the preparation of a supported $\mathrm{Ru}$ catalyst $(\mathrm{Ru} / \mathrm{HZSM}-5-\mathrm{H})$, and applied it in alkene di-functionalization to synthesize seleno- and sulfurcontaining compounds. As a comparison, $\gamma-\mathrm{Al}_{2} \mathrm{O}_{3}, \mathrm{H}$-form microporous zeolite ZSM-5 (HZSM-5) and basic ETS-10 supported Ru catalysts $\left(\mathrm{Ru} / \gamma-\mathrm{Al}_{2} \mathrm{O}_{3}, \mathrm{Ru} / \mathrm{HZSM}-5\right.$, and $\mathrm{Ru} / \mathrm{ETS}-10$, 
respectively) were also prepared. The catalytic results show that the $\mathrm{Ru} / \mathrm{HZSM}-5-\mathrm{H}$ catalyst has higher reaction activity and product selectivity compared to that of the $\mathrm{Ru} / \gamma-\mathrm{Al}_{2} \mathrm{O}_{3}$, $\mathrm{Ru} / \mathrm{HZSM}-5, \mathrm{Ru} / \mathrm{ETS}-10$ and $\mathrm{RuCl}_{3}$ catalysts. These features could be attributed to the fact that the relatively strong acidic sites in Ru/HZSM-5-H benefit the adsorption of styrene and activate its $\mathrm{C}=\mathrm{C}$ bond, improving the reaction activity. In addition, the $\mathrm{Ru}^{4+}$ species in the form of an oxide on the $\mathrm{Ru}$ / HZSM-5-H catalyst could favor the transformation of diaryl diselenides to electrophilic selenium species that can attack the activated $\mathrm{C}=\mathrm{C}$ bond in styrene to form the desired product.

\section{Experimental}

\subsection{Material synthesis}

The hierarchical zeolite ZSM-5 (ZSM-5-H) was synthesized in a gel with a composition of $\mathrm{Al}_{2} \mathrm{O}_{3}: 89 \mathrm{SiO}_{2}: 24 \mathrm{Na}_{2} \mathrm{O}: 3$ TPAOH : 0.07 COPQA : $3200 \mathrm{H}_{2} \mathrm{O}$ in a $100 \mathrm{~L}$ stainless steel autoclave. TPAOH is tetrapropylammonium hydroxide and was used as a microporous template agent. COPQA is a mesoscale template, and is a cationic copolymer containing quaternary ammonium groups that are synthesized from diallylamine and dimethyl diallylammonium chloride. ${ }^{26}$ In a typical run, 8.85 L of water glass, $1.4 \mathrm{~L}$ of TPAOH (25.0 wt\%) and 5.6 $\mathrm{L}$ of $\mathrm{H}_{2} \mathrm{O}$ were sequentially added to the autoclave and stirred for $1 \mathrm{~h}$, then $4.3 \mathrm{~L}$ of COPQA was slowly added, and the mixture was further stirred for $2 \mathrm{~h}$. Then, $19 \mathrm{~L}$ of acidic aluminum sulfate solution $\left(0.03 \mathrm{~mol} \mathrm{~L}^{-1}\right)$ was slowly added and the obtained mixture was stirred for $2 \mathrm{~h}$. After that, the obtained aluminosilicate gel underwent dynamic crystallization in the autoclave at $170{ }^{\circ} \mathrm{C}$ for $44 \mathrm{~h}$. The solid product was collected through filtration, washing, and drying, followed by calcination in air at $550{ }^{\circ} \mathrm{C}$ for $5 \mathrm{~h}$ to remove the template agent. The microporous zeolite ZSM- 5 was synthesized by the same procedure except for the addition of the mesoscale template COPQA. Titanosilicate zeolite ETS-10, which consists of corner-sharing tetrahedral $\left(\mathrm{SiO}_{4}\right)$ and octahedral $\left(\mathrm{TiO}_{6}\right)^{2-}$ links through bridging oxygen atoms, was prepared according to the previously reported literature. ${ }^{27} \gamma-\mathrm{Al}_{2} \mathrm{O}_{3}$ was purchased from Shanghai HENGYE Chemical Industry Co., Ltd. The zeolite was ion-exchanged with $1 \mathrm{M} \mathrm{NH}_{4} \mathrm{NO}_{3}$ solution at $80{ }^{\circ} \mathrm{C}$ for $1 \mathrm{~h}$, followed by filtration, drying and calcination at $500{ }^{\circ} \mathrm{C}$ for $4 \mathrm{~h}$. This procedure was repeated twice to obtain $\mathrm{H}$-form zeolites (HZSM-5-H and HZSM-5).

\subsection{Catalyst preparation}

The catalyst was prepared using the incipient wetness method through the impregnation of the supports with an aqueous solution containing an appropriate amount of ruthenium chloride $\left(\mathrm{RuCl}_{3} \cdot 3 \mathrm{H}_{2} \mathrm{O}\right)$. The $\mathrm{Ru}$ loading was $3.0 \mathrm{wt} \%$. The impregnated sample was dried at room temperature for $24 \mathrm{~h}$ and subsequently dried in an oven at $100{ }^{\circ} \mathrm{C}$ for $12 \mathrm{~h}$. After that, the sample was calcined at $450{ }^{\circ} \mathrm{C}$ for $4 \mathrm{~h}$. The resulting samples with different supports were denoted as Ru/HZSM-5-H, Ru/ HZSM-5, Ru/ETS-10 and $\mathrm{Ru} / \gamma-\mathrm{Al}_{2} \mathrm{O}_{3}$.

\subsection{Characterization}

$\mathrm{X}$-Ray powder diffraction (XRD) patterns were recorded on a $\mathrm{D} /$ MAX 2500/PC powder diffractometer (Rigaku) using a $\mathrm{Cu} \mathrm{K} \alpha$ radiation source operating at $40 \mathrm{kV}$ and $200 \mathrm{~mA}$. The crystallite size of the ruthenium oxide particles was determined using the peak at $2 \theta=34.9^{\circ}$ and the Scherrer equation, $D_{\mathrm{c}}=K \lambda / \beta \cos (\theta)$, where $K$ is a constant taken as $0.9, \lambda$ is the wavelength of the $\mathrm{X}$ ray radiation, $\beta$ is the width of the peak at half-maximum, and $2 \theta$ is the Bragg angle. Nitrogen physisorption was conducted at $-196{ }^{\circ} \mathrm{C}$ using Micromeritics ASAP2020M apparatus. The sample was degassed for $8 \mathrm{~h}$ at $300{ }^{\circ} \mathrm{C}$ before the measurements were taken. The specific surface area was calculated from the adsorption data using the Brunauer-Emmett-Teller (BET) equation.

The acidities of the supports and catalysts were measured using ammonia temperature-programmed desorption $\left(\mathrm{NH}_{3}\right.$ TPD) on a Micromeritics ASAP2920 instrument. Typically, $200 \mathrm{mg}$ of the sample was placed in a quartz tube and pretreated in a helium stream at $450{ }^{\circ} \mathrm{C}$ for $2 \mathrm{~h}$. After the sample was cooled to $120{ }^{\circ} \mathrm{C}$, an $\mathrm{NH}_{3}-\mathrm{He}$ gas mixture $\left(10 \mathrm{vol} \% \mathrm{NH}_{3}\right)$ was flowed over the sample for $30 \mathrm{~min}$. After removing the physically adsorbed $\mathrm{NH}_{3}$ by flowing helium for $2 \mathrm{~h}$ at $120^{\circ} \mathrm{C}$, the sample was heated from 120 to $530{ }^{\circ} \mathrm{C}$ at a rate of $10{ }^{\circ} \mathrm{C} \mathrm{min}{ }^{-1}$. The desorbed $\mathrm{NH}_{3}$ was collected in dilute hydrochloric acid and titrated with a dilute sodium hydroxide solution to determine the acidic site density of the sample. The obtained $\mathrm{NH}_{3}$-TPD curve of the supports was deconvoluted at different maximum peak temperatures with a Gaussian function for fitting, and the peak areas were calculated. ${ }^{\mathbf{2 8 , 2 9}}$ The acidic nature (Brønsted/ Lewis) of the supports and catalysts was investigated through pyridine adsorption infrared spectroscopy (Py-IR) on a Bruker TENSOR 27 spectrophotometer equipped with a reactor cell. The experiment procedure was as follows: the sample was pressed into self-supporting wafers and degassed under vacuum $\left(1 \times 10^{-2} \mathrm{~Pa}\right)$ at $100{ }^{\circ} \mathrm{C}$ for $1 \mathrm{~h}$, and subsequently exposed to pyridine vapor after being cooled to $30^{\circ} \mathrm{C}$. The Py-IR spectrum was then recorded at $30{ }^{\circ} \mathrm{C}$ after the sample was placed under vacuum at $30{ }^{\circ} \mathrm{C}$ for $30 \mathrm{~min}$.

Temperature-programmed reduction (TPR) of the catalyst was performed with a Micromeritics ASAP2920 instrument using a $\mathrm{H}_{2}-\mathrm{Ar}$ gas mixture $\left(10\right.$ vol\% $\left.\mathrm{H}_{2}\right)$. The calcined sample (40 mg) was heated from room temperature to $800{ }^{\circ} \mathrm{C}$ at a heating rate of $10^{\circ} \mathrm{C} \mathrm{min}^{-1}$. The ratio of $\mathrm{Si} / \mathrm{Al}(\mathrm{Ti})$ of the zeolite as well as the Ru content of the sample were determined using inductively coupled plasma optical emission spectroscopy (ICPOES) with a Perkin-Elmer 3300DV emission spectrometer.

Scanning electron microscopy (SEM) images of the sample were obtained on a field-emission scanning electron microscope (SUPRA55) operating at an acceleration voltage of $5 \mathrm{kV}$. Transmission electron microscopy (TEM) images were obtained on a JEM-2100 microscope with a limited line resolution capacity of $1.4 \AA$ at $200 \mathrm{kV}$. Before it was characterized, the sample was cut into thin slices and dropped onto a $\mathrm{Cu}$ grid that was coated with carbon membrane.

The infrared (IR) spectrum of the styrene-adsorbed $\mathrm{Ru} /$ HZSM-5-H sample was obtained on a Bruker TENSOR 27 
infrared spectrophotometer equipped with a reactor cell. Before the measurements were taken, the sample was evacuated to $10^{-2} \mathrm{~Pa}$ at $50{ }^{\circ} \mathrm{C}$ for $20 \mathrm{~h}$. The spectrum was obtained in the absorbance mode and was shown after the subtraction of a background spectrum that was obtained on the corresponding HZSM-5-H sample. For comparison, the spectra of styrene and ethylbenzene were recorded at room temperature. The ultraviolet-visible diffuse reflectance spectrum (UV-Vis) was obtained using a Shimadzu UV-3600 spectrometer. X-ray photoelectron spectroscopy (XPS) experiments were performed using an ESCALAB MK II system.

\subsection{Activity tests}

All of the materials were of analytical grade and were used as received without further purification. The typical experimental procedure for the seleno-functionalization of styrene was as follows: catalyst $(25 \mathrm{mg})$, styrene $1 \mathrm{a}(1.0 \mathrm{mmol})$, diaryl diselenides $2 \mathrm{a}(0.6 \mathrm{mmol}), \mathrm{H}_{2} \mathrm{O}_{2}(1.5 \mathrm{mmol}, 30 \%$ aqueous solution), acetonitrile $(1 \mathrm{~mL})$ and $\mathrm{H}_{2} \mathrm{O}(1 \mathrm{~mL})$ were placed in a sealed tube $(10 \mathrm{~mL})$. The reaction proceeded at $60{ }^{\circ} \mathrm{C}$ for the desired time. After the reaction finished, the reaction mixture was separated using centrifugation and extraction to obtain the products in the liquid phase. The liquid products were analyzed using an Agilent 1260 Infinity Liquid Chromatogram. The pure product was obtained with flash column chromatography on silica gel using petroleum ether $\left(60-90{ }^{\circ} \mathrm{C}\right)$ and ethyl acetate as the eluents. The compounds that are described in the literature were characterized by comparing their ${ }^{1} \mathrm{H}$ NMR (500, 400 and $300 \mathrm{MHz}$ ) and ${ }^{13} \mathrm{C}$ NMR $(125,100$ and $75 \mathrm{MHz})$ spectra, which were recorded with spectrometers at $20{ }^{\circ} \mathrm{C}$ using $\mathrm{CDCl}_{3}$ as the solvent. The chemical shifts were given in parts per million relative to TMS as the internal standard at room temperature.

\subsection{Adsorption experiments}

The typical adsorption experimental procedure was carried out as follows: $0.1 \mathrm{~g}$ of the catalyst and $4 \mathrm{mg}$ of styrene were dissolved in acetonitrile $(10 \mathrm{~mL})$ in a $25 \mathrm{~mL}$ sealed tube with stirring. The adsorption time was $3 \mathrm{~h}$ at $60^{\circ} \mathrm{C}$. After cooling to room temperature, the liquid phase was separated from the reaction mixture using centrifugation, and was analyzed with an Agilent 7890B GC. The solid sample was washed with acetonitrile (15 $\mathrm{mL}$ ) as many times as possible to eliminate the physically adsorbed styrene, and was dried at $50{ }^{\circ} \mathrm{C}$ for $24 \mathrm{~h}$ and evacuated to $10^{-2} \mathrm{~Pa}$ at $50{ }^{\circ} \mathrm{C}$ for $20 \mathrm{~h}$. The resulting solid sample was used for UV-Vis and IR characterization.

\section{Results and discussion}

\subsection{Characterization}

In Fig. 1a, the XRD patterns of ZSM-5-H and ZSM-5 show typical diffraction peaks in the range $5-50^{\circ}$ associated with an MFI structure, ${ }^{26}$ which is in line with the reference ZSM-5 (PDF\#440003). The isotherms of ZSM-5-M show the appearance of a hysteresis loop at $P / P_{0}=0.6-0.96$, suggesting the presence of a mesoporous structure in the zeolite crystals (Fig. 1b), and the corresponding mesoporous size is mainly centered at $22 \mathrm{~nm}$
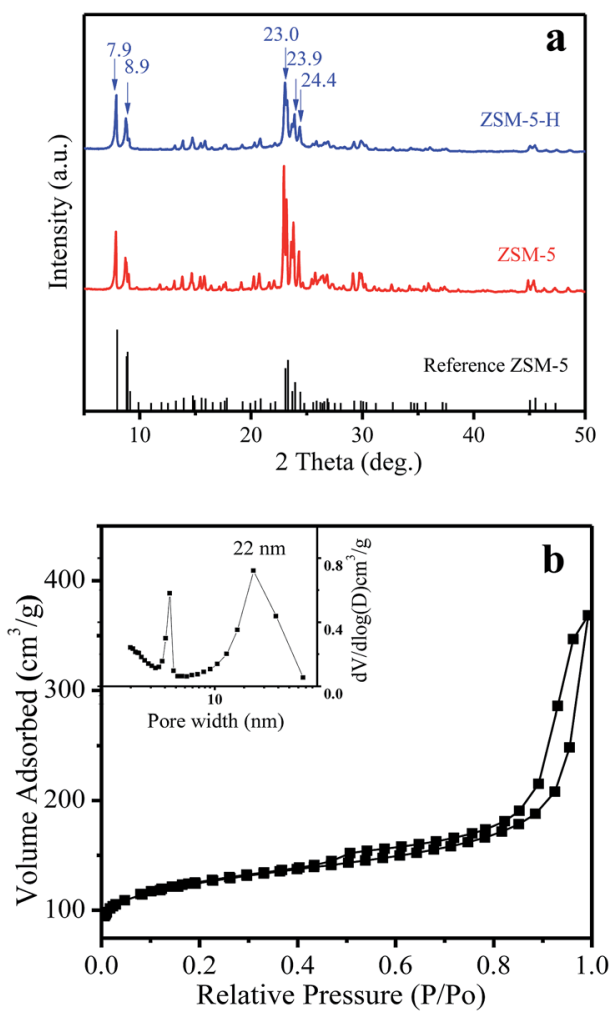

Fig. 1 (a) XRD patterns of the reference ZSM-5 (PDF\#44-0003), ZSM5 and ZSM-5-H samples, (b) $\mathrm{N}_{2}$ adsorption isotherms of the ZSM-5-H sample (pore size distribution, inset).

(Fig. 1b, inset). The texture parameters for all of the samples are listed in Table S1. $\uparrow \mathrm{ZSM}-5-\mathrm{H}$ has an external surface area of 208 $\mathrm{m}^{2} \mathrm{~g}^{-1}$ and a mesoporous volume of $0.47 \mathrm{~cm}^{3} \mathrm{~g}^{-1}$, while the bulk ZSM-5 only has a low external surface area $\left(45 \mathrm{~m}^{2} \mathrm{~g}^{-1}\right.$, Table S1 and Fig. S1 $\dagger$ ). The SEM image shows that the large ZSM-5-H particles are formed by the aggregation of small nanocrystals with sizes of 50-250 nm, and meso- and macropores are formed between these aggregated particles (Fig. 2a). Interestingly, the TEM image shows that many intra-crystalline mesopores (light areas) also existed in the ZSM-5-H crystals (Fig. 2b). The abundant mesopores and macropores in ZSM-5-H could benefit the diffusion of the bulky reactant molecule.

The $\mathrm{NH}_{3}$-TPD curves in Fig. 3a show that HZSM-5-H and HZSM-5 have similar desorption profiles with peaks around 224,325 and $406{ }^{\circ} \mathrm{C}$, indicating the presence of sites with weak, medium and strong acidity on the HZSM-5-H and HZSM-5 samples, respectively. In contrast, a desorption profile with only a peak at $243{ }^{\circ} \mathrm{C}$ and a shoulder peak at $357^{\circ} \mathrm{C}$ appears in the $\mathrm{NH}_{3}$-TPD curve of $\gamma-\mathrm{Al}_{2} \mathrm{O}_{3}$, suggesting the presence of sites with weak and medium acidity on $\gamma-\mathrm{Al}_{2} \mathrm{O}_{3}$, respectively. The acid-base titration results in Table S2 $\uparrow$ show that HZSM-5 (580 $\left.\mu \mathrm{mol} \mathrm{g}^{-1}\right)$ and HZSM-5-H $\left(500 \mu \mathrm{mol} \mathrm{g}^{-1}\right)$ have higher total acidic site densities than $\gamma-\mathrm{Al}_{2} \mathrm{O}_{3}\left(480 \mu \mathrm{mol} \mathrm{g}{ }^{-1}\right)$. After the loading of $\mathrm{Ru}$, the total acidic site density on the catalysts is lower than that on the corresponding supports. Nevertheless, the acidic site densities on Ru/HZSM-5 $\left(480 \mu \mathrm{mol} \mathrm{g}^{-1}\right)$ and $\mathrm{Ru} /$ HZSM-5-H $\left(420 \mu \mathrm{mol} \mathrm{g}{ }^{-1}\right)$ are higher than that on $\mathrm{Ru} / \gamma-\mathrm{Al}_{2} \mathrm{O}_{3}$ 


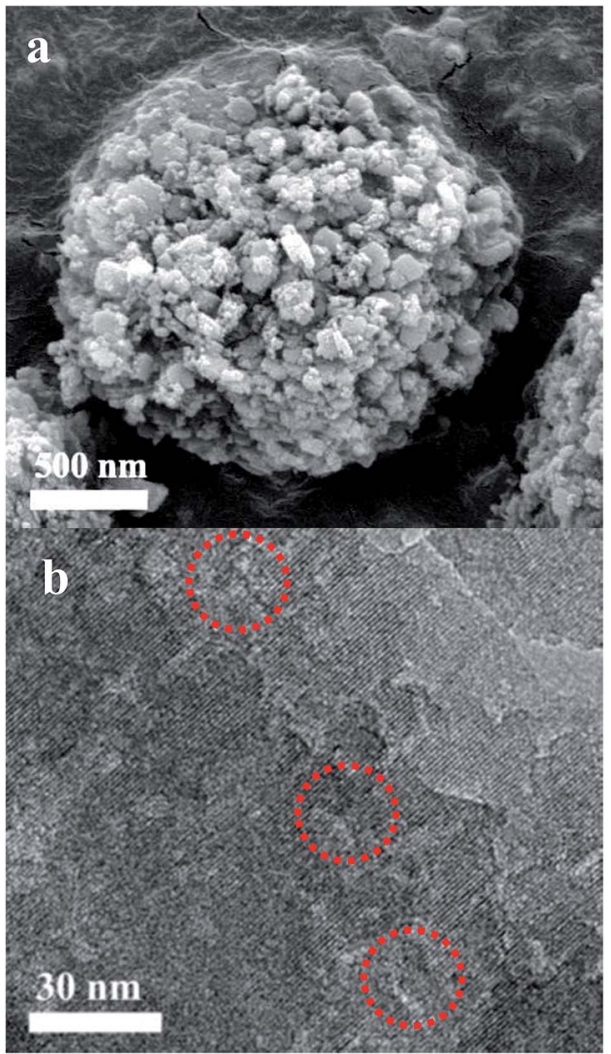

Fig. 2 (a) SEM image of the ZSM-5-H sample and (b) a TEM image of a thin slice of the ZSM-5-H zeolite.

$\left(340 \mu \mathrm{mol} \mathrm{g}{ }^{-1}\right)$. It is notable that the $\mathrm{NH}_{3}$-desorption peak appears at 262,296 and $300{ }^{\circ} \mathrm{C}$ for $\mathrm{Ru} / \gamma-\mathrm{Al}_{2} \mathrm{O}_{3}, \mathrm{Ru} / \mathrm{HZSM}-5-\mathrm{H}$ and Ru/HZSM-5, respectively, which indicates that the acidic strength of Ru/HZSM-5 and Ru/HZSM-5-H is stronger than that of $\mathrm{Ru} / \gamma-\mathrm{Al}_{2} \mathrm{O}_{3}$ (Fig. 3b). The Py-IR spectra in Fig. 4 show absorption bands at 1445 and $1546 \mathrm{~cm}^{-1}$, which are attributed to pyridine that is adsorbed on the Lewis acid and Brønsted acid sites of the zeolites and the catalysts, ${ }^{29,30}$ while there are only Lewis sites on the $\gamma-\mathrm{Al}_{2} \mathrm{O}_{3}$ and $\mathrm{Ru} / \gamma-\mathrm{Al}_{2} \mathrm{O}_{3}$ samples (Fig. $\mathrm{S} 2 \dagger$ ).

Fig. 5 shows the XRD patterns of the various catalysts. Clearly, two diffraction peaks at $2 \theta=27.9$ and $34.9^{\circ}$ that are associated with ruthenium oxide are present in the XRD patterns of the $\mathrm{Ru} / \mathrm{HZSM}-5, \mathrm{Ru} / \mathrm{HZSM}-5-\mathrm{H}$ and $\mathrm{Ru} / \gamma-\mathrm{Al}_{2} \mathrm{O}_{3}$ catalysts, ${ }^{31}$ indicating that relatively large ruthenium oxide particles were formed after the catalyst precursor was calcined at $450{ }^{\circ} \mathrm{C}$. The corresponding particle sizes that were calculated using the Scherrer equation are 20.4, 17.2 and $16.5 \mathrm{~nm}$ for the $\mathrm{Ru} / \mathrm{HZSM}-5, \mathrm{Ru} / \mathrm{HZSM}-5-\mathrm{H}$ and $\mathrm{Ru} / \gamma-\mathrm{Al}_{2} \mathrm{O}_{3}$ catalysts, respectively (for details please see the ESI, Fig. S3 and S4†). In contrast, the diffraction peaks of ruthenium oxide were not detected in the XRD spectra for the Ru/ETS-10 catalyst (for details please see the ESI, Fig. S5†), indicating that relatively small Ru particles were formed. When the Ru loading was reduced in Ru/HZSM-5$\mathrm{H}$, the particle size of the ruthenium oxide decreased (Fig. S6 $†$ ). The TEM images of the supported Ru catalysts show that Ru particles with sizes of 5-25 $\mathrm{nm}$ were irregularly located in the mesopores and on the outer surface of Ru/HZSM-5-H (Fig. 6a),
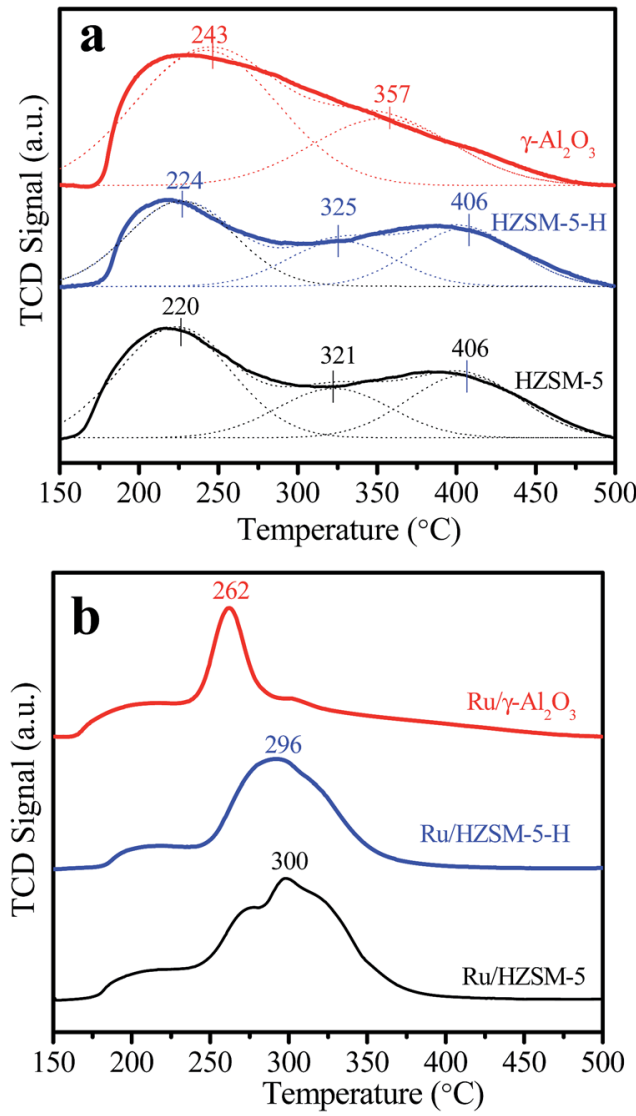

Fig. 3 (a) $\mathrm{NH}_{3}$-TPD curves and Gaussian deconvoluted peaks of the different supports and (b) the $\mathrm{NH}_{3}$-TPD curves of the different catalysts.

and relatively large $\mathrm{Ru}$ particles were dispersed on the outer surface of Ru/HZSM-5 (Fig. 6b). The Ru particles having a crystal lattice spacing of $0.32 \mathrm{~nm}$ is consistent with the $d$-spacing of the $\mathrm{RuO}_{2}\{110\}$ crystallographic plane (Fig. 6b, inset). ${ }^{32,33}$ In addition, the size distributions of $\mathrm{RuO}_{2}$ on the $\mathrm{Ru} / \mathrm{HZSM}-5-\mathrm{H}$ and $\mathrm{Ru} / \mathrm{HZSM}-5$ catalysts were also obtained using statistical analyses from the TEM images (Fig. S7 $\dagger$ ), and the average $\mathrm{RuO}_{2}$ particle size $\left(D_{\text {aver. }}\right)$ was $17.9 \mathrm{~nm}$ on Ru/HZSM-5-H and $23.3 \mathrm{~nm}$ on Ru/HZSM-5.

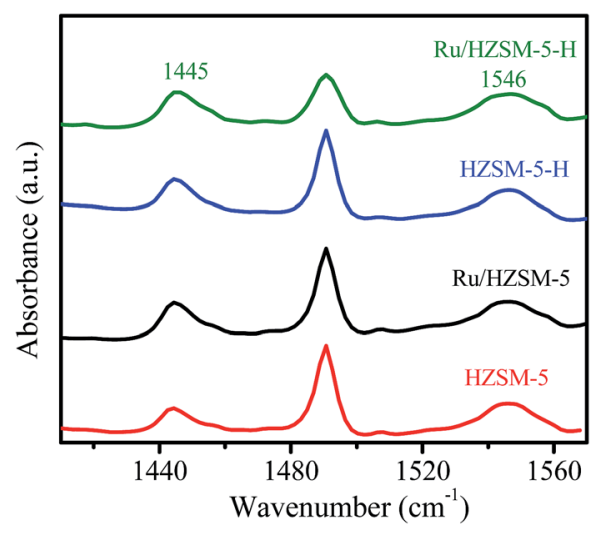

Fig. 4 Py-IR spectra of the supports and catalysts. 


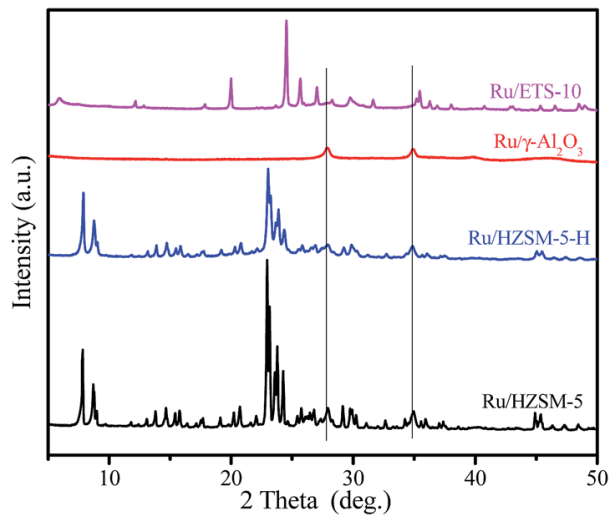

Fig. 5 XRD patterns of the various catalysts.

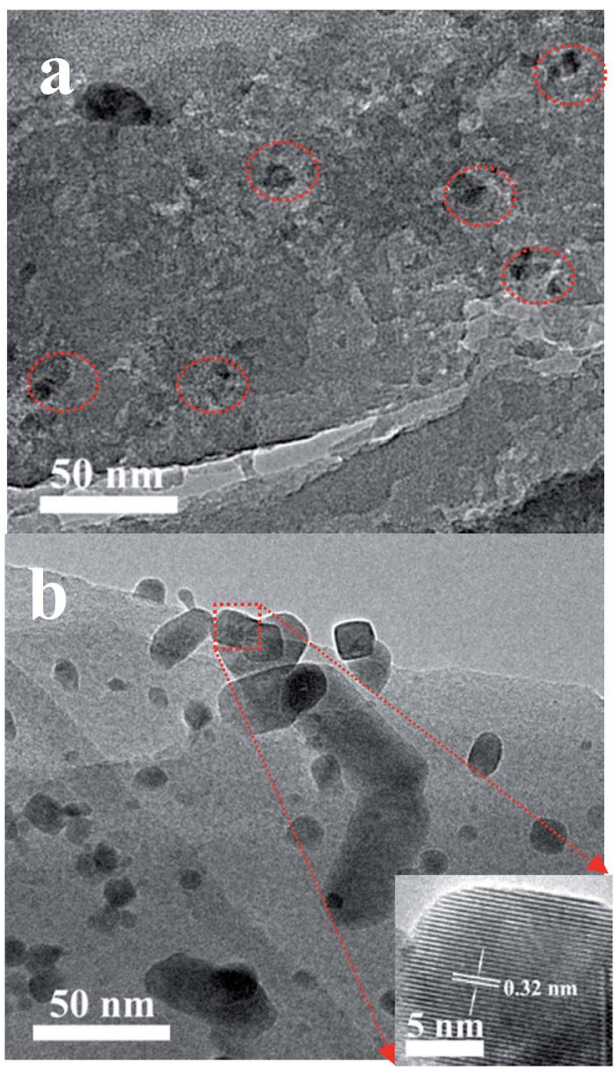

Fig. 6 TEM images of the (a) Ru/HZSM-5-H and (b) Ru/HZSM-5 samples.

The electronic states of the $\mathrm{Ru}$ species on the different catalysts were investigated using XPS, and the results are shown in Fig. 7. The binding energy at $462.7 \mathrm{eV}$ is related to $\mathrm{Ru}^{4+}$ in the form of $\mathrm{RuO}_{2}$ on $\mathrm{Ru} / \mathrm{HZSM}-5-\mathrm{H}, \mathrm{Ru} / \mathrm{HZSM}-5$ and Ru/ETS-10. ${ }^{34-36}$ However, another binding energy at $460.3 \mathrm{eV}$ that is assigned to $\mathrm{Ru}^{0}$ is also present in the XPS spectrum of Ru/ETS-10, indicating some $\mathrm{Ru}^{0}$ species existed on Ru/ETS-10. ${ }^{34-36}$ This could be due to the fact that the strong Lewis basic sites on ETS-10 (ref. 27) can partially reduce ruthenium oxide to $\mathrm{Ru}^{0}$ species during the catalyst preparation process.

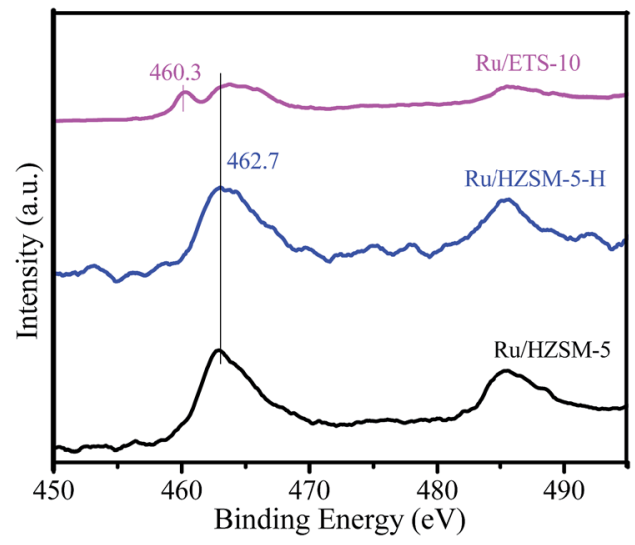

Fig. 7 XPS spectra of Ru $3 p_{3 / 2}$ for the various catalysts.

\subsection{Catalytic performance}

The catalytic performance of the Ru/HZSM-5-H catalyst in alkene difunctionalization was tested firstly by choosing the hydroxyselenation of styrene with diaryl diselenide (Table 1). The initial results show that moderate styrene conversion (51\%) and product 3a selectivity (72\%) were achieved without the use of a catalyst (entry 1). When using $\mathrm{RuCl}_{3}$ salt as the catalyst, although the styrene conversion did not change, the 3a selectivity increased to $96 \%$, indicating that the $\mathrm{Ru}^{3+}$ species is beneficial for the improvement of reaction selectivity. When acidic HZSM-5-H was employed as the catalyst, the styrene conversion (65\%) slightly increased, but the 3a selectivity did not obviously improve $(78 \%$, entry 3$)$. It is notable that the styrene conversion (94\%) and 3a selectivity (95\%) significantly improved when the strongly acidic $\mathrm{Ru} / \mathrm{HZSM}-5-\mathrm{H}$ catalyst was used (entry 4). The reduced Ru/HZSM-5-H catalyst was also tested in this reaction, and the reaction activity (48\%) and product selectivity (67\%) did not improve (entry 5). These results indicate that, compared with $\mathrm{Ru}^{0}$ species in reduced $\mathrm{Ru}$ / HZSM-5-H (Fig. S8 $\dagger$ ), $\mathrm{Ru}^{4+}$ in the form of $\mathrm{RuO}_{2}$ on the Ru/HZSM5-H catalyst can significantly improve the reaction activity and product selectivity. In addition, although Ru/HZSM-5 has a similar acidity to $\mathrm{Ru} / \mathrm{HZSM}-5-\mathrm{H}$, the reaction activity is relatively lower (67\%, entry 6$)$, which could be due to the fact that, compared with Ru/HZSM-5 with a low external area $\left(37 \mathrm{~m}^{2} \mathrm{~g}^{-1}\right)$, $\mathrm{Ru} / \mathrm{HZSM}-5-\mathrm{H}$ has a large mesoporous surface area $\left(162 \mathrm{~m}^{2} \mathrm{~g}^{-1}\right)$ and mesoporous volume $\left(0.4 \mathrm{~cm}^{3} \mathrm{~g}^{-1}\right.$, Table $\left.\mathrm{S} 1 \dagger\right)$, and the abundant mesopores not only benefit the reactants' easy access to the acidic sites, but also facilitate the mass transfer of the bulk reactant and product, improving its catalytic performance. Compared to strongly acidic Ru/HZSM-5-H, weakly acidic $\mathrm{Ru} / \gamma$ $\mathrm{Al}_{2} \mathrm{O}_{3}$ has a large mesoporous surface area $\left(332 \mathrm{~m}^{2} \mathrm{~g}^{-1}\right.$, Table $\mathrm{S} 1 \dagger$ ) and presents similar $\mathrm{RuO}_{2}$ particles (Fig. 5), but the styrene conversion on this catalyst is lower (48\%, entry 7$)$. Furthermore, the styrene conversion on the strongly basic Ru/ETS-10 catalyst is very low (entry 8), which indicates that a catalyst with basicity could disfavour this transformation. In addition, the effect of $\mathrm{Ru}$ loading in the catalyst on the catalytic performance was also investigated (Table S3†). The styrene conversion increased with the Ru loading in the Ru/HZSM-5-H catalyst. 
Table 1 Hydroxyselenation of styrene with diaryl diselenide over a series of catalysts $^{a}$

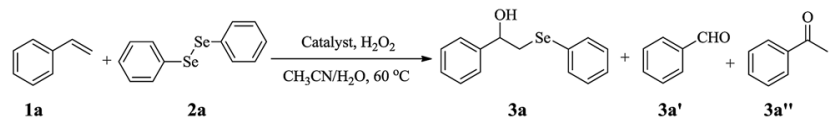

\begin{tabular}{|c|c|c|c|c|c|c|}
\hline \multirow[b]{2}{*}{ Entry } & \multirow[b]{2}{*}{ Catalyst } & \multirow[b]{2}{*}{ Conv. $^{b}(\%)$} & \multicolumn{3}{|c|}{ Selectivity $^{c}(\%)$} & \multirow[b]{2}{*}{ Ad. capacity ${ }^{f}\left(\mathrm{mg} \mathrm{g}_{\text {cat. }}{ }^{-1}\right)$} \\
\hline & & & $3 \mathbf{a}$ & $3 \mathbf{a}^{\prime}$ & $3 \mathbf{a}^{\prime \prime}$ & \\
\hline 1 & - & 51 & 72 & 25 & 3 & - \\
\hline 2 & $\mathrm{RuCl}_{3}{ }^{d}$ & 50 & 96 & 2 & 2 & - \\
\hline 3 & HZSM-5-H & 65 & 78 & 20 & 2 & - \\
\hline 4 & Ru/HZSM-5-H & 94 & 95 & 2 & 3 & 20 \\
\hline 5 & $\mathrm{Ru} / \mathrm{HZSM}-5-\mathrm{H}^{e}$ & 48 & 67 & 11 & 22 & - \\
\hline 6 & Ru/HZSM-5 & 67 & 80 & 10 & 10 & - \\
\hline 7 & $\mathrm{Ru} / \gamma-\mathrm{Al}_{2} \mathrm{O}_{3}$ & 48 & 52 & 22 & 20 & 9.5 \\
\hline 8 & $\mathrm{Bu} / \mathrm{FTS}-10$ & 15 & 78 & 18 & 4 & 12 \\
\hline
\end{tabular}

${ }^{a}$ Reaction conditions: $25 \mathrm{mg}$ of solid catalyst, styrene (1.0 mmol), diaryl diselenides $(0.6 \mathrm{mmol}), \mathrm{H}_{2} \mathrm{O}_{2}(1.5 \mathrm{mmol}), \mathrm{H}_{2} \mathrm{O}(1.0 \mathrm{~mL}), \mathrm{CH} \mathrm{CN}(1.0 \mathrm{~mL})$, and $7 \mathrm{~h}$. The carbon in the reaction mixture is balanced. ${ }^{b}$ The conversion was analyzed using LC. ${ }^{c}$ The product selectivity was analyzed using LC. ${ }^{d}$ The $\mathrm{Ru}$ content was equal to the Ru content in the $25 \mathrm{mg}$ of solid catalyst. ${ }^{e} \mathrm{Ru} / \mathrm{HZSM}-5-\mathrm{H}$ was reduced at $150{ }^{\circ} \mathrm{C}$ for $2 \mathrm{~h}$ in a $\mathrm{H}_{2}$ stream (the temperature programmed reduction profile is shown in Fig. S7). ${ }^{f}$ The adsorption capacity of styrene (1a) on the catalysts.

The above results imply that the strongly acidic sites and the $\mathrm{Ru}^{4+}$ species on the $\mathrm{Ru} / \mathrm{HZSM}-5-\mathrm{H}$ catalyst could play synergistic catalytic roles, which enhance the reaction activity and selectivity. In the difunctionalization of styrene with diaryl diselenide, the $\mathrm{C}=\mathrm{C}$ bond activation in styrene should be a key step. In this case, the activated $\mathrm{C}=\mathrm{C}$ bond is easily attacked by electrophilic selenium species. In our case, the abundant strongly acidic sites on HZSM-5-H favor the styrene adsorption and activation of the $\mathrm{C}=\mathrm{C}$ bond. This suggestion was supported by the investigation of styrene adsorption experiments, as well as the UV-Vis and IR spectra of styrene adsorbed on the $\mathrm{Ru} /$ HZSM-5-H sample (Ru/HZSM-5-H-1a).

From Table 1, the adsorption capacity of styrene (1a) on $\mathrm{Ru} /$ HZSM-5-H (20 mg $\left.\mathrm{g}_{\text {cat. }}{ }^{-1}\right)$ is much higher than that on $\mathrm{Ru} / \gamma$ $\mathrm{Al}_{2} \mathrm{O}_{3}$ (9.5 $\mathrm{mg} \mathrm{g}_{\text {cat. }}{ }^{-1}$ ) and $\mathrm{Ru} / \mathrm{ETS}-10$ (1.2 $\mathrm{mg} \mathrm{g}_{\text {cat. }}{ }^{-1}$ ). More valuable information is obtained from the UV-Vis and IR spectra of $\mathrm{Ru} / \mathrm{HZSM}-5-\mathrm{H}-1 \mathrm{a}$. From Fig. 8a, the absorption band at $258 \mathrm{~nm}$ for pure styrene, assigned to the conjugate $\pi$ bond resulting from the $\mathrm{C}=\mathrm{C}$ bond and benzene ring in styrene, was shifted to $245 \mathrm{~nm}$ for the Ru/HZSM-5-H-1a sample. This could be due to the fact that the conjugate $\pi$ bond between the $\mathrm{C}=\mathrm{C}$ bond and benzene ring in styrene was destroyed when the styrene was adsorbed on Ru/HZSM-5-H, resulting in the occurrence of a blue shift. Thus, the $\mathrm{C}=\mathrm{C}$ bond in styrene could be activated on the acidic sites of the Ru/HZSM-5-H catalyst. This suggestion was further confirmed using the IR characterization of the $\mathrm{Ru} / \mathrm{HZSM}-5-\mathrm{H}-1 \mathrm{a}$ sample. The IR spectrum of pure styrene 1a shows an absorption band in the $3004-3104 \mathrm{~cm}^{-1}$ region, which is characteristic of the stretching vibrations of $\mathrm{C}-\mathrm{H}$ in a benzene ring, ${ }^{17}$ and the band at $2978 \mathrm{~cm}^{-1}$ is assigned to the stretching vibration of $\mathrm{C}-\mathrm{H}$ in the $\mathrm{C}=\mathrm{C}$ bond (Fig. 8b). ${ }^{37-39}$ In contrast, two new bands at 2862 and $2937 \mathrm{~cm}^{-1}$ appear in the spectrum of the Ru/HZSM-5-H-1a sample. Similar absorption bands at 2873 and $2931 \mathrm{~cm}^{-1}$ are observed in the spectrum of ethylbenzene, which are related to the $\mathrm{C}-\mathrm{H}$ stretching vibrations in methyl and methylene in ethylbenzene (Fig. 4b). ${ }^{37-39}$ These results confirm that the $\mathrm{C}=\mathrm{C}$ bond in styrene was activated on the acidic Ru/HZSM-5-H catalyst.

The activated $\mathrm{C}=\mathrm{C}$ bond in styrene could be easily attacked by the electrophilic selenium species to form an intermediate that was reacted with a nucleophilic reagent to form the target product (the proposed mechanism is shown in Fig. S9†).
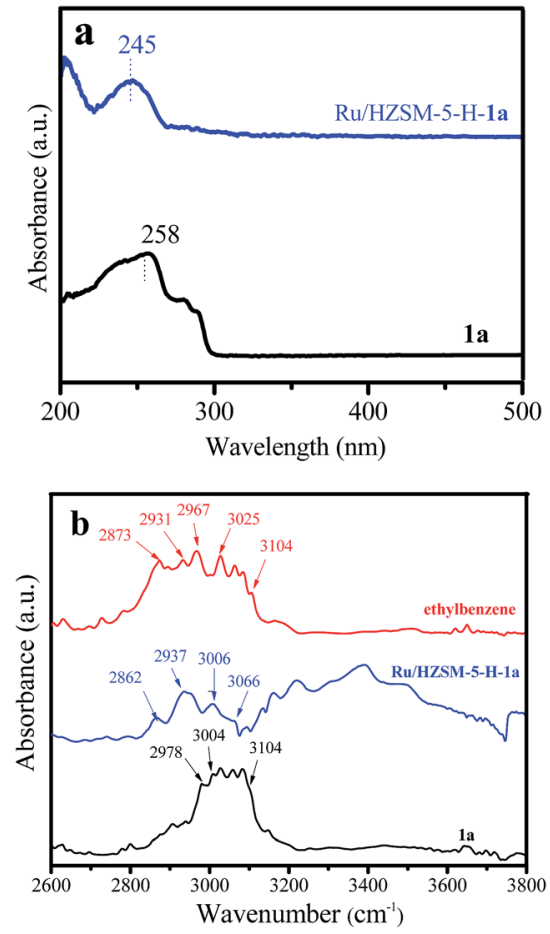

Fig. 8 (a) UV-Vis spectra of the styrene (1a) and Ru/HZSM-5-H-1a samples, and (b) the IR spectra of the $1 a$, ethylbenzene and Ru/HZSM5-H-1a samples. 
Meanwhile, compared with the $\mathrm{Ru}^{0}$ species, the electron-poor $\mathrm{Ru}^{4+}$ species can act as a Lewis acid or co-oxidant that could more easily facilitate the formation of electrophilic selenium species in the case of $\mathrm{H}_{2} \mathrm{O}_{2}$ oxidizing the diaryl diselenides (Fig. S9†). As a result, the reaction activity and selectivity (94 and 95\%) on $\mathrm{Ru} / \mathrm{HZSM}-5-\mathrm{H}$ is much higher than those (48 and 67\%) on reduced $\mathrm{Ru} / \mathrm{HZSM}-5-\mathrm{H}$.

The scope of this hydroxyselenation reaction over the $\mathrm{Ru} /$ HZSM-5-H catalyst was investigated, and the results are summarized in Table 2. The $\mathrm{Ru} / \mathrm{HZSM}-5-\mathrm{H}$ catalyst tolerates various styrenes with electron-donating substituents, such as methoxy, methyl, tertiary butyl and acetoxy groups, leading to high activity and target product selectivity (3b-3f). Meanwhile, styrenes with halogen substituents (3g-3i) at the ortho, meta and para positions also afforded the desired products in good to high yields. Other types of alkenes with polycyclic components such as biphenyl, naphthalene and diyldibenzene were compatible, affording good yields of the target products $(\mathbf{3} \mathbf{j}-\mathbf{3 l})$. Interestingly, this protocol was also applicable to $\alpha$-methylstyrene, affording the desired product in gratifying yield (3m). Meanwhile, the substrates of cyclohexene and methylenecyclopentane were also suitable for this transformation and gave the products in good yields (3n, 3o). Notably, the reagent 4pentenoic acid containing an internal nucleophile was also successfully applied to this transformation, resulting in the cyclo-functionalization of alkenes and the formation of selenolactone in moderate yield (3p).

The generality of the $\mathrm{Ru} / \mathrm{HZSM}-5-\mathrm{H}$ catalyst in the difunctionalization of alkenes was further investigated through choosing alkoxy and carbethoxy groups as nucleophiles (Table 3). From Table 3, different alcohols such as methanol, ethanol, iso-propanol and phemethylol were used as reaction solvents, and they were also shown to be very good nucleophiles for this transformation, giving the corresponding selenofunctionalization compounds in satisfactory yields (4a-4d). In addition, styrenes with methoxyl or bromine substituent groups were also successfully reacted with methanol and diaryl diselenides, delivering the desired products in $62-66 \%$ yield (4e, 4f). Furthermore, 2-vinylnaphthalene with large molecular dimensions and cyclohexene were also smoothly reacted with methanol and diaryl diselenides $(\mathbf{4 g}, \mathbf{4 h})$. Very interestingly, the displacement of the alcohol by the nucleophilic acetic acid could also be successfully applied to different alkenes such as styrene, $p$-bromo-styrene, 2-vinylnaphthalene and cyclohexene in the seleno-functionalization reactions, which furnished good substrate conversions and product selectivities (4i-4l). Notably, the styrenes with 4- $\mathrm{CH}_{3}$ - and 4-Cl-substituent groups also smoothly reacted with diaryl disulfides in the presence of the methoxyl nucleophile, giving the sulfur-functionalization compounds in good yields (Table $\mathrm{S} 4 \dagger$ ).

The results from Tables 2 and 3 indicate that Ru/HZSM-5-H has a broad scope in the difunctionalization of alkenes. In addition, the reusable ability of the Ru/HZSM-5-H catalyst in the hydroxyselenation of styrenes with diaryl diselenides was also performed (Table S5 $\dagger$ ). The Ru/HZSM-5-H catalyst exhibits high activity (90\%) and product selectivity (91\%) even after it was recycled seven times, indicating that the $\mathrm{Ru} / \mathrm{HZSM}-5-\mathrm{H}$ catalyst
Table 2 Hydroxyselenation of alkenes with diaryl diselenide on the $\mathrm{Ru} / \mathrm{HZSM}-5-\mathrm{H}$ catalyst $^{a}$

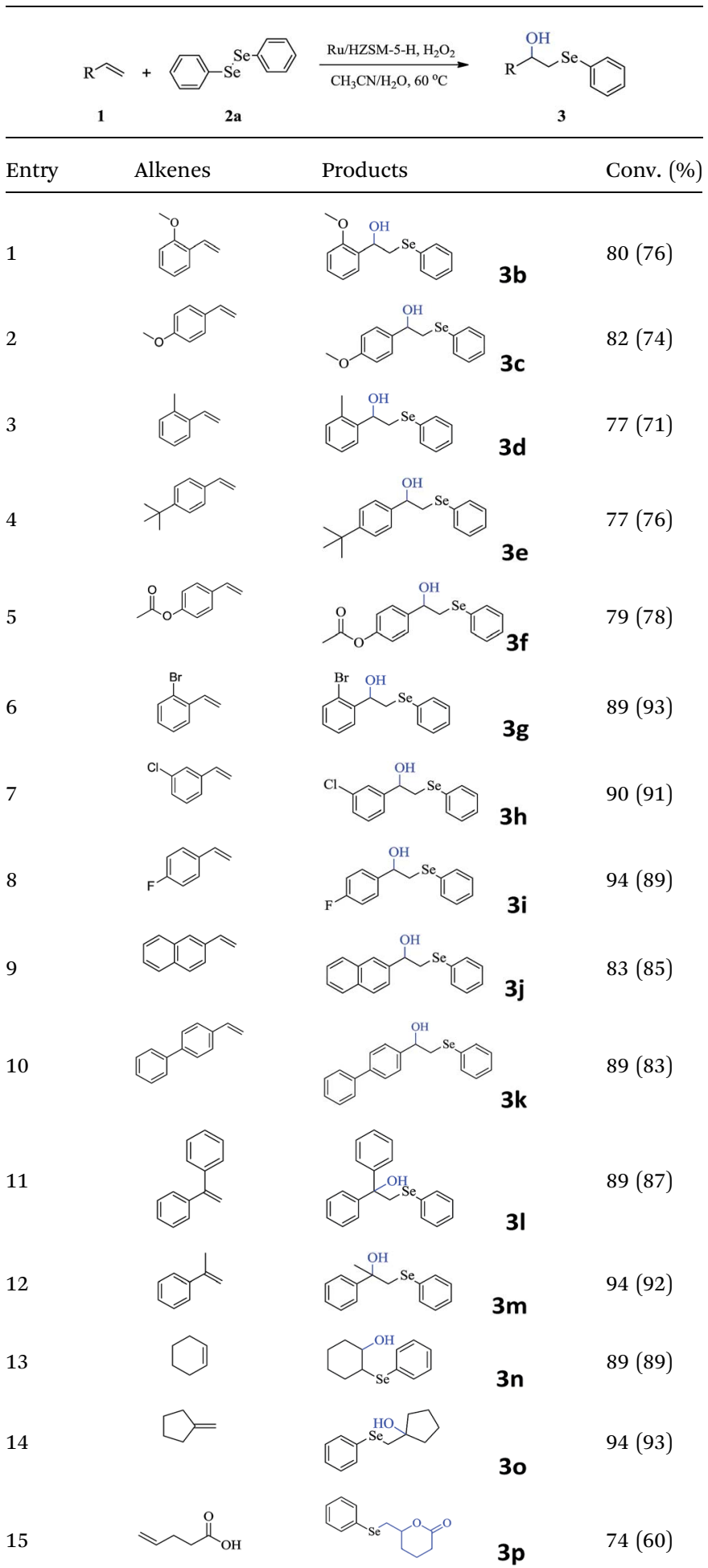

${ }^{a}$ Reaction conditions: $25 \mathrm{mg}$ of solid catalyst, alkenes $(1.0 \mathrm{mmol})$, diaryl diselenides $(0.6 \mathrm{mmol}), \mathrm{H}_{2} \mathrm{O}_{2}(1.5 \mathrm{mmol}), \mathrm{H}_{2} \mathrm{O}(1.0 \mathrm{~mL})$, $\mathrm{CH}_{3} \mathrm{CN}(1.0 \mathrm{~mL})$, and $60{ }^{\circ} \mathrm{C}$ for $10 \mathrm{~h}$. The data outside of the parentheses is the conversion, and the data in parentheses is the selectivity. 
Table 3 Alkoxy-selenation and carbethoxy-selenation of alkenes with diaryl diselenides on the Ru/HZSM-5-H catalyst ${ }^{a}$

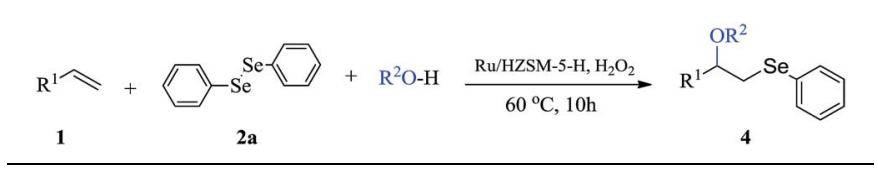

$\begin{array}{llll}\text { Entry Alkenes } & \text { Solvent } & \text { Products } & \text { Conv. (\%) }\end{array}$

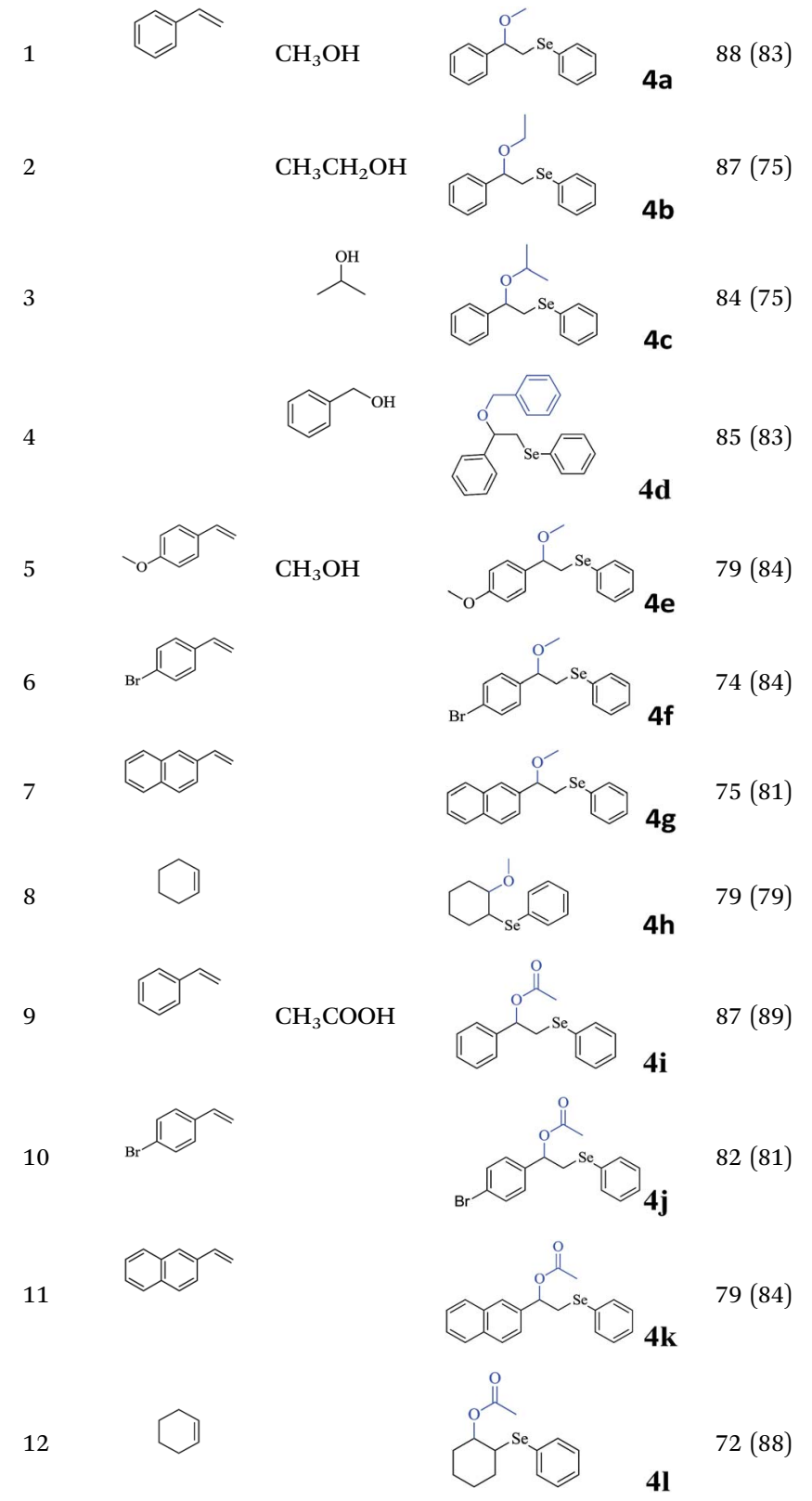

\footnotetext{
${ }^{a}$ Reaction conditions: $25 \mathrm{mg}$ of solid catalyst, alkenes ( $\left.1.0 \mathrm{mmol}\right)$, diaryl diselenides $(0.6 \mathrm{mmol}), \mathrm{H}_{2} \mathrm{O}_{2}(1.5 \mathrm{mmol})$, alcohols or acetic acid $(2.0$ $\mathrm{mL}$ ), and $60{ }^{\circ} \mathrm{C}$ for $10 \mathrm{~h}$. The data outside of the parentheses is the conversion, and the data in parenthesis is the selectivity.
}

has a good reusability. Nevertheless, the $\mathrm{Ru}$ content in the reused $\mathrm{Ru} / \mathrm{HZSM}-5-\mathrm{H}$ catalyst that was recycled seven times is only $2.5 \mathrm{wt} \%$. The parallel experiments over the Ru/HZSM-5-H catalyst in the hydroxyselenation of styrene with diaryl diselenides were performed, and the results are shown in Table S6. $\dagger$ The reproducibility over the Ru/HZSM-5-H catalyst is good, and the error bars for the styrene conversion and selectivity are 0.41 and 0.48 .

\section{Conclusions}

In summary, an acidic Ru/HZSM-5-H catalyst shows high activity and product selectivity in the hydroxyselenation of styrenes with diaryl diselenides compared to $\mathrm{Ru} / \mathrm{ETS}-10, \mathrm{Ru} / \gamma$ $\mathrm{Al}_{2} \mathrm{O}_{3}, \mathrm{Ru} / \mathrm{HZSM}-5$ and homogeneous $\mathrm{RuCl}_{3}$ catalysts. The relatively strong acidic sites on $\mathrm{Ru} / \mathrm{HZSM}-5-\mathrm{H}$ could benefit the adsorption of styrene and activate its $\mathrm{C}=\mathrm{C}$ bond, increasing the reaction activity. Meanwhile, the $\mathrm{Ru}^{4+}$ in $\mathrm{Ru} / \mathrm{HZSM}-5-\mathrm{H}$ facilitates the transformation from diaryl diselenides to electrophilic selenium species, improving the catalytic activity and selectivity. Furthermore, Ru/HZSM-5-H not only has a broad scope in the difunctionalization of alkenes with diaryl diselenides in the presence of hydroxyl, alkoxy and carbethoxy groups, but also has relatively good reusability.

\section{Acknowledgements}

This work was supported by the National Natural Science Foundation of China (U1463203, 21476030 and U1662139) and the Natural Science Foundation of Jiangsu Province of China (BK20150258).

\section{Notes and references}

1 K. Okamoto, Y. Nishibayashi, S. Uemura and A. Toshimitsu, Angew. Chem., Int. Ed., 2005, 44, 3588-3591.

2 F. Wang, D. Wang, X. Mu, P. Chen and G. Liu, J. Am. Chem. Soc., 2014, 136, 10202-10205.

3 X. Sun, X. Li, S. Song, Y. Zhu, Y.-F. Liang and N. Jiao, J. Am. Chem. Soc., 2015, 137, 6059-6066.

4 C. W. Nogueira, G. Zeni and J. B. T. Rocha, Chem. Rev., 2004, 104, 6255-6285.

5 B. C. Ranu and T. Mandal, J. Org. Chem., 2004, 69, 5793-5795.

6 B. Das, V. S. Reddy and R. Ramu, J. Mol. Catal. A: Chem., 2007, 263, 276-278.

7 T. Wirth, G. Fragale and M. Spichty, J. Am. Chem. Soc., 1998, 120, 3376-3381.

8 T. G. Back and Z. Moussa, Org. Lett., 2000, 2, 3007-3009.

9 B. C. Ranu, T. Mandal and S. Samanta, Org. Lett., 2003, 5, 1439-1441.

10 M. Tingoli, R. Diana and B. Panunzi, Tetrahedron Lett., 2006, 47, 7529-7531.

11 E. Tang, Y. Zhao, W. Li, W. Wang, M. Zhang and X. Dai, Org. Lett., 2016, 18, 912-915.

12 A. A. Vieira, J. B. Azeredo, M. Godoi, C. Santi, E. N. S. Júnior and A. L. Braga, J. Org. Chem., 2015, 80, 2120-2127.

13 M. J. Climent, A. Corma and S. Iborra, Chem. Rev., 2011, 111, 1072-1133.

14 À. Molnár, Chem. Rev., 2011, 111, 2251-2320. 
15 Q. Wu, X. Wang, G. Qi, Q. Guo, S. Pan, X. Meng, J. Xu, F. Deng, F. Fan, Z. Feng, C. Li, S. Maurer, U. Müller and F.-S. Xiao, J. Am. Chem. Soc., 2014, 136, 4019-4025.

16 Y. Wei, T. E. Parmentier, K. P. Jong and J. Zečević, Chem. Soc. Rev., 2015, 44, 7234-7261.

17 T. Tang, L. Zhang, H. Dong, Z. Fang, W. Fu, Q. Yu and T. Tang, RSC Adv., 2017, 7, 7711-7717.

18 L. Wang, J. Zhang, X. Yi, A. Zheng, F. Deng, C. Chen, Y. Ji, F. Liu, X. Meng and F.-S. Xiao, ACS Catal., 2015, 5, 27272734.

19 S. Chen, Z. Shao, Z. Fang, Q. Chen, T. Tang, W. Fu, L. Zhang and T. Tang, J. Catal., 2016, 338, 38-46.

20 W. Fu, T. Liu, Z. Fang, Y. Ma, X. Zheng, W. Wang, X. Ni, M. Hu and T. Tang, Chem. Commun., 2015, 51, 5890-5893.

21 X. Zheng, W. Fu, J. Xiong, J. Xi, X. Ni and T. Tang, Catal. Today, 2016, 264, 152-157.

22 W. Fu, Y. Feng, Z. Fang, Q. Chen, T. Tang, Q. Yu and T. Tang, Chem. Commun., 2016, 52, 3115-3118.

23 T. Liu, W. Fu, X. Zheng, J. Jiang, M. Hu and T. Tang, RSC Adv., 2014, 4, 18217-18221.

24 H. Li, Y. Wang, F. Meng, H. Chen, C. Sun and S. Wang, RSC Adv., 2016, 6, 99129-99138.

25 A. Li, C. Huang, C.-W. Luo, W.-J. Yia and Z.-S. Chao, RSC $A d v .$, 2017, 7, 9551-9561.

26 W. Fu, L. Zhang, D. Wu, Q. Yu, T. Tang and T. Tang, Ind. Eng. Chem. Res., 2016, 55, 7085-7095.
27 M. Xiang, X. Ni, X. Yi, A. Zheng, W. Wang, M. He, J. Xiong, T. Liu, Y. Ma, P. Zhu, X. Zheng and T. Tang, ChemCatChem, 2015, 7, 521-525.

28 M. D. Romero, J. A. Calles and A. Rodríguez, Ind. Eng. Chem. Res., 1997, 36, 3533-3540.

29 Y. Wang, Z. Tao, B. Wu, J. Xu, C. Huo, K. Li, H. Chen, Y. Yang and Y. Li, J. Catal., 2015, 322, 1-13.

30 H. Song, J. Wang, Z. Wang, H. Song, F. Li and Z. Jin, J. Catal., 2014, 311, 257-265.

31 C.-P. Lo and V. Ramani, ACS Appl. Mater. Interfaces, 2012, 4, 6109-6116.

32 N. Taniguchi, J. Org. Chem., 2006, 71, 7874-7876.

33 R. Mu, D. C. Cantu, X. Lin, V.-A. Glezakou, Z. Wang, I. Lyubinetsky, R. Rousseau and Z. Dohnálek, J. Phys. Chem. Lett., 2014, 5, 3445-3450.

34 X. Zhang and K.-Y. Chan, Chem. Mater., 2003, 15, 451-459.

35 J. Yang, J. Y. Lee, T. C. Deivaraj and H.-P. Too, J. Colloid Interface Sci., 2004, 271, 308-312.

36 K. Qadir, S. H. Joo, B. S. Mun, D. R. Butcher, J. R. Renzas, F. Aksoy, Z. Liu, G. A. Somorjai and J. Y. Park, Nano Lett., 2012, 12, 5761-5768.

37 A. Mallmann and D. Barthomeuf, Zeolites, 1988, 8, 292-301.

38 W. P. Addiego, C. A. Estrada, D. W. Goodman and M. P. Rosynek, J. Catal., 1994, 146, 407-414.

39 I. Retzko, J. F. Friedrich, A. Lippitz and W. E. S. Unger, J. Electron Spectrosc. Relat. Phenom., 2001, 121, 111-129. 